\title{
COVID-19, Chronic Conditions and Structural Poverty: A Social Psychological Assessment of the Needs of a Marginalized Community in Accra, Ghana
}

\author{
Ama de-Graft Aikins ${ }^{1}$, Olutobi Sanuade ${ }^{2}$, Leonard Baatiema ${ }^{3}$, Paapa Yaw Asante ${ }^{4}$, Francis Agyei ${ }^{4}$, Vida Asah-Ayeh ${ }^{4}$, \\ Jemima A. O. Okai ${ }^{5}$, Annabella Osei-Tutu ${ }^{4}$, Kwadwo Koram ${ }^{6}$ \\ [1] Institute of Advanced Studies, University College London, London, United Kingdom. [2] Institute for Global Health, University College London, London, United \\ Kingdom. [3] Department of Health Planning Policy, Planning and Management, School of Public Health, University of Ghana, Accra, Ghana. [4] Department of \\ Psychology, University of Ghana, Accra, Ghana. [5] School of Public Service and Governance, Ghana Institute of Management and Public Administration, Accra, \\ Ghana. [6] Noguchi Memorial Institute for Medical Research, University of Ghana, Accra, Ghana.
}

Journal of Social and Political Psychology, 2021, Vol. 9(2), 577-591, https://doi.org/10.5964/jspp.7543

Received: 2020-09-01 • Accepted: 2021-04-13 • Published (VoR): 2021-11-25

Handling Editor: Puleng Segalo, University of South Africa, Pretoria, South Africa

Corresponding Author: Ama de-Graft Aikins, Institute of Advanced Studies, Room 15, South Wing, Wilkins Building, University College London, Gower Street, London WC1E 6BT, United Kingdom. E-mail: a.de-graft-aikins@ucl.ac.uk

\begin{abstract}
In the African region COVID-19 infection and death rates are increasing (writing in May 2020), most deaths have occurred among individuals with chronic conditions, and poor communities face higher risks of infection and socio-economic insecurities. We assessed the psychosocial needs of a chronic illness support group in Accra, Ghana, within the context of their broader community. The community lives in structural poverty and has a complex burden of infectious and chronic non-communicable diseases (NCDs). Between March and May 2020, we conducted interviews, group discussions, and surveys, with members of the support group and their caregivers, frontline healthcare workers, and religious and community leaders. Data was analysed through the social psychology of participation framework. Community members understood COVID-19 as a new public health threat and drew on eclectic sources of information to make sense of this. Members of the support group had psychosocial and material needs: they were anxious about infection risk as well as money, food and access to NCD treatment. Some community members received government food packages during the lockdown period. This support ended after lockdown in April and while anti-poverty COVID policies have been unveiled they have yet to be implemented. We discuss the impact of these representational, relational and power dynamics on the community's access to COVID-19 and NCD support. We argue that strategies to address immediate and post-COVID needs of vulnerable communities have to focus on the politics and practicalities of implementing existing rights-based policies that intersect health, poverty reduction and social protection.
\end{abstract}

\section{Keywords}

COVID-19, chronic conditions, community participation, power, social capital, social representations, structural poverty, health systems, Ghana

Globally, over 23 million cases and 800,000 deaths due to the coronavirus disease (COVID-19) are reported in over 200 countries, at the time of writing in August 2020 (WHO, 2020). Research in the countries hardest hit by the COVID-19 pandemic suggests that the risk of critical illness and premature death following COVID-19 infection is high for older individuals (aged 60+), men, and individuals living with pre-existing chronic conditions, chiefly, hypertension, heart problems, diabetes, asthma and obesity (Clark et al., 2020). This risk intensifies if individuals live in structural poverty (Braveman, 2020; Fernandez, 2020). Over the last two decades, research on the global burden of chronic non-communi- 
cable diseases (NCDs) suggests that the pre-existing chronic conditions associated with severe COVID-19 outcomes are disproportionately experienced by low- and middle-income countries (LMICs) of Africa, Asia and Latin America (Bukhman et al., 2015). In these contexts, while wealthy communities experience NCD risk, poor communities live with a double burden of infectious and chronic conditions compounded by poor access to healthcare and catastrophic healthcare costs. Therefore, the multidimensional impact of the COVID pandemic is likely to be greatest on poor communities and older populations in LMICs with a chronic disease burden (Lloyd-Sherlock et al., 2020).

The first two cases of COVID-19 were reported in Ghana on $12^{\text {th }}$ March 2020. The government imposed strong prevention measures including border closures, a ban on public gatherings, partial lockdown and quarantining of travellers (Kenu et al., 2020). However, cases have steadily increased. At the time of writing, at the end of August 2020, 43,325 cases and 261 deaths are reported and Ghana is fourth on the top 10 list of African countries hardest hit by the pandemic; just over 1 million cases and 20,000 deaths have been reported in 45 African countries (WHO, 2020). While early cases were 'imported' via travellers from endemic European and Asian countries, community spread has been established with reports of infection in poor communities in the capital Accra and other towns. There have been no formal reports of COVID-19 deaths in poor communities. However underlying chronic conditions - hypertension, diabetes and asthma - are implicated in serious illness and deaths (Oduro-Mensah et al., 2020)1.

Ghana, like many African countries, has a complex convergence of demographic, developmental, epidemiological and health systems challenges. The country's health system struggles to address a complex disease burden, of infectious diseases, chronic diseases, over and undernutrition driven by urban poverty, ageing, food insecurity and rising levels of common mental disorders (de-Graft Aikins \& Koram, 2017). While social and health protection policies exist, implementation is poor (Alidu et al., 2016; de-Graft Aikins \& Koram, 2017). Therefore, the country is ill prepared to treat large numbers of critical COVID-19 cases, provide adequate social protection for the working poor, health protection for populations living with chronic conditions, and social care for the elderly.

In this paper we report key findings of a social psychological assessment of the needs of a chronic illness support group in Ga Mashie, one of the oldest communities in Accra, Ghana. The support group, established in 2016, has members who live with hypertension, diabetes, asthma and post-stroke conditions. At the last national census, in 2010, Ga Mashie occupied the fourth and lowest income class within the Accra Metropolitan Area, with an average monthly household income of GHC126.13 (US\$78.83) (de-Graft Aikins et al., 2015). About three quarters of the population have received Junior High School, or middle school, education and higher. The main economic activities are fishing and petty trading. Infectious diseases like malaria co-exist with a growing prevalence of chronic diseases like hypertension and diabetes. Hypertension prevalence is $28.3 \%$ (women at $25.6 \%$, men at $31 \%$ ) and diabetes prevalence was $5 \%$ (with men at $3.8 \%$ and women at $5.5 \%$ ) (Awuah et al., 2014). These rates are comparable to the national prevalence rates for hypertension (25\% - 48\%), obesity (15.3 among women) and diabetes (6\% - 9\%) (Awuah et al., 2014).

This study builds on previous research in the community that has examined chronic disease risk, experiences and care, including through a 'social psychology of participation' model (Campbell \& Jovchelovitch, 2000; de-Graft Aikins et al., 2020). The research has included the establishment of the support group, called Jamestown Health Club, and facilitation of monthly group meetings since 2016.

The study had four aims: (1) examine community understandings of COVID-19 risk, treatment and care; (2) assess needs of the support group; (3) assess available community and national resources available to support the support group during the pandemic and (4) offer practical recommendations.

\section{Conceptual Framework}

\section{COVID-19 and the Ghanaian Context}

The Ghanaian government's early national response to COVID-19 was strong and exemplary. In addition to early commitments to public health prevention - including border closures, quarantining, contact tracing and partial lockdown - investments were made in protecting frontline healthcare workers, supporting small and informal businesses,

1) Authors' analysis of Ghana Health Service data 
and educating the nation through regular and clear messaging from the president and Ministry of Information. The key government messages relevant to poor communities included: establishing a COVID-19 National Trust Fund; the suspension of utility bills for three months (April to June, 2020); and the provision of PPE to frontline healthcare workers. In April, the government secured a USD $\$ 1$ billion loan from the International Monetary Fund (IMF) to address the economic impact of COVID-19 (IMF, 2020). It was reported that this loan would support small businesses, and infrastructure development including building new hospitals in underserved districts. The COVID-19 National Fund, established to "receive contributions and donations from the public to assist in the welfare of the needy and the vulnerable during the COVID-19 period" had raised GHS50.6 million $(\$ 606,000)$ by July 2020 (CitiNewsroom, 2020).

We tracked official government communication and mass media narratives on social and health protection for vulnerable communities, as well as evolving public understandings of the pandemic (de-Graft Aikins \& Akoi-Jackson, 2020). This provided the structural context to examine practical solutions for the research community.

\section{Social Psychology of Participation}

We applied the social psychology of participation approach to the community assessment. Proposed by Campbell and Jovchelovitch (2000), this approach aims to integrate individual, inter-individual and macro-social levels of analyses in community health participation under conditions of poverty. Three social psychological features are essential for analyses: identity, local knowledge and power.

Identity denotes the ways in which a community conceives of, and articulates itself. Community identity is typically heterogenous and hierarchical, and informs complex social relations, knowledge and practices in everyday life.

Local knowledge or social representations, shapes a community's worldview and its interpretation of social reality and everyday practices. Like identity, local (everyday) knowledge/social representations in community settings, are expected to be heterogeneous, dynamic and contradictory. This character of everyday knowledge is captured in the concept of 'cognitive polyphasia', defined as the state in which different kinds of knowledge, with inherently divergent or contradictory rationalities, coexist in the minds of the same individual or group (Jovchelovitch, 2002).

Power structures community life in terms of conditions and constraints of access to material (e.g., money) and symbolic (e.g., respect) resources. Campbell and Jovchelovitch apply Bourdieu's notion of social capital to examinations of power. Social capital, defined as "unequally distributed resources associated with people's participation in social networks in unequal social settings" can mediate social inequalities and individual health at three interrelated levels: "as bonding networks of solidarity uniting people within marginalised communities, as bridging networks uniting groups of people (more or less equal in terms of power and status) across marginalised communities; and as linking networks connecting marginalised people to more powerful champions" (Campbell, 2020). Alliances with "powerful champions" whether they are located at the national or global levels, can amplify the "voices of vulnerable communities...to achieve a meaningful balance of top-down and bottom-up perspectives" towards social change (Campbell, 2020).

To place group and community responses to COVID-19 in structural context, and to identify "powerful champions" for COVID-19 interventions, we examined global and national strategies and policies on COVID-19, in addition to the evolution of national responses described previously. Data collection and analysis were informed by guidelines from the World Health Organization (WHO), and credible national institutions including the Ghana Health Service (GHS), the Food and Drugs Authority (FDA), the Noguchi Memorial Institute for Medical Research (NMIMR) and official national associations of doctors, nurses and pharmacists.

\section{Method}

\section{Research Participants and Methodological Approach}

Research participants included Jamestown Health Club (hereafter JTHC) members and their caregivers, representatives of major health facilities providing healthcare in the community, religious leaders and other community leaders. 
We applied a mixed method and iterative approach, combining interviews, group discussions, surveys and a psychosocial needs assessment. Table 1 describes the research methods and target social groups. Table 2 presents the socio-demographic profiles of JTHC members.

Table 1

Methods and Community Participants

\begin{tabular}{ll}
\hline Method & Social groups/ focus \\
\hline Group discussions & JTHC members $(n=19)$ \\
& Church leaders $(n=7)$ \\
& Mosque leaders $(n=3)$ \\
Interviews & Market queen \\
& Representative for fishermen's association \\
& Representative of GAMADA \\
Surveys & Healthcare workers $(n=15)$ \\
& $(1$ government clinic, 4 private clinics, 4 private pharmacies, 4 LCS shops, 2 herbal shops \\
Psychosocial needs assessment & JTHC members $(n=36)$ \\
& Caregivers $(n=5)$ \\
\hline
\end{tabular}

\section{Table 2}

Sociodemographic Details of JTHC Members

\begin{tabular}{lc}
\hline Categories & $\boldsymbol{n}$ \\
\hline Age & 5 \\
$40-49$ years & 20 \\
$50-59$ years & 11 \\
$60+$ years & 32 \\
\hline Gender & 4 \\
$\quad$ Female & \\
Male & \\
\hline Employment status & 24 \\
Trading & 1 \\
Creative industries & 1 \\
Local leadership & \\
Retired & \\
\hline Conditions (s) & \\
Hypertension & \\
Hypertension and Diabetes & 11 \\
Hypertension and Asthma & \\
Hypertension and Mild Stroke & \\
Diabetes & \\
Stroke & 1 \\
\hline
\end{tabular}




\begin{tabular}{lc}
\hline Categories & $n$ \\
\hline Primary caregiver $^{\mathbf{a}}$ & \\
$\quad$ Spouse & 3 \\
Child & 25 \\
Grandchild & 2 \\
Sibling & 8 \\
Mother & 2 \\
Niece & \\
Relative (unspecified) & 1 \\
\hline
\end{tabular}

${ }^{\mathrm{a}}$ Four individuals had more than 1 caregiver.

The guides for the group discussions and interviews explored three broad themes summarised in Box 1. Each encounter ended with an educational session with key elements synthesised from WHO educational material and adapted for the Ga Mashie context. For each targeted group, specific questions were asked under each broad theme.

Box 1

Focus Group Discussion and Interview Guides: Key Themes

- exploring existing knowledge of the coronavirus pandemic (nature of the pandemic, affected countries and communities, Ghanaian government policies)

- exploring understanding of risk and vulnerable groups (focus on categories of vulnerable groups, elderly individuals, individuals with chronic conditions)

- exploring knowledge of health protection (probes focus on 6 areas outlined by the WHO: physical/social distancing, hand washing, respiratory hygiene, avoiding touching one's face, home hygiene, quarantining/selfisolation and knowing COVID-19 hotspots)

- exploring current and anticipated practical responses to coronavirus (including resources for protection at individual, household, community and health facility levels)

The survey for healthcare providers constituted a basic checklist of coronavirus preparedness, with key questions drawn from WHO guidelines for health facilities and frontline healthcare workers. A summary of the questions is presented in Appendix 1.

The community was reported to have at least 60 pluralistic health facilities in 2014 (de-Graft Aikins et al., 2015). These included one government owned polyclinic, private clinics, private pharmacies, licensed chemical sellers (LCS), churches, mosques and traditional shrines. We reached a third of facilities that are regularly used by community members, as outlined in Table 1. We excluded traditional shrines in the initial assessment. Shrines are located within the compounds of households. We gathered data just after the first two cases were reported in Ghana and before lockdown was imposed in Accra. We did not want to increase COVID-19 risk for the community and research team by engaging in household spaces.

\section{Data Collection}

Data was gathered and analysed between $13^{\text {th }}$ March and $4^{\text {th }}$ May 2020 and in three stages. English and local languages $\mathrm{Ga}$ and Twi were used in community engagement. Some community interactions were tape recorded; others were recorded in note form. All interviews and discussions were conducted with participants' consent, and all ethical protocols were observed.

Stage 1: Initial community assessment with JTHC members, community healthcare workers, community members and religious leaders. On $12^{\text {th }}$ March 2020, a day before fieldwork began, Ghana's 2 first cases were reported. By $15^{\text {th }}$ 
March the cases had risen to 6 and the government had imposed a ban on public gatherings, including religious services. We gathered two sets of data from JTHC members, healthcare facilities, and Christian and Muslim leaders on $13^{\text {th }}$ and $15^{\text {th }}$ March. We then had one physical engagement when we delivered hand sanitisers to JTHC members on $24^{\text {th }}$ March: physical distancing rules were observed to ensure the safety of recipients and team members. After this date all data was gathered remotely via telephone.

Stage 2: We followed up on interviews with additional community leaders and external actors listed in Table 1. As outlined in the conceptual section, we tracked official government communication and mass media narratives on social and health protection for vulnerable communities to examine potential advocacy routes for Ga Mashie.

Stage 3: We conducted a psychosocial needs assessment with JTHC members between $9^{\text {th }}$ and $16^{\text {th }}$ April. The interviews focused on three areas: material, medical and psychological (see Appendix 2 for the full guide).

\section{Data Analysis}

We applied a theory-driven thematic analysis to the data. In examining community understandings, we focused on the content of local knowledge, the sources of knowledge and the articulated functions of knowledge. We also focused on the relationship between knowledge and social identities by examining how knowledge was structured across different social groups, for example individuals with chronic conditions, healthcare workers, and religious leaders. Previous research in the community has described local knowledge of diabetes, CVD and stroke as cognitive polyphasic, with community members blending cultural, religious, common sense and medical knowledge in their understanding of these conditions (de-Graft Aikins et al., 2015, 2020; Sanuade et al., 2021). Sources of knowledge are equally broad and complex, including family and social networks, traditional media, and local and external pluralistic healthcare systems. In analysing the content and sources of knowledge on COVID-19 we focused on these existing insights, but also paid attention to potentially new sources and types of knowledge. In analysing functions of knowledge, we focused on: (1) how individuals were acting, at the time of data collection, on the knowledge they had about COVID-19 (e.g., handwashing, practising physical distancing, stigmatising practices); and (2) factors enabling and undermining health-protective actions.

On power, we applied the concepts of productive alliances and social capital (bonding, bridging and linking) to examine concrete and anticipated forms of support and factors enabling or hindering these forms of support. We identified 'powerful champions' - internal and external actors who were likely to play a role in COVID-19 responses, based on what JTHC members said and on previous research in the community.

During data collection and early-stage data analysis, we held weekly online team meetings to review and reflect on emerging insights from data collection. Minutes of our meetings contributed to our collective fieldnotes. This informed responsive changes to our research methods, the structure and contents of the training manual for conducting the psychosocial needs assessment, broader community engagement and engagement with evolving government policy and media narratives.

Analysis was conducted iteratively, as data was collected and through the weekly team discussions. After the final needs assessment session was conducted and case notes were analysed, the data set was synthesised along three themes: (1) community understandings of COVID-19; (2) material and psychosocial needs of JTHC members; and (3) feasible productive alliances for COVID-19 support in the community. The results are presented under these three themes.

\section{Results}

\section{Community Understandings of COVID-19}

All the community members we engaged with had heard of the COVID-19 pandemic before the first two cases were reported in Ghana on $12^{\text {th }}$ March 2020. 
Most people knew the following:

- washing hands with soap and water frequently;

- covering the nose with a handkerchief or tissue when coughing;

- avoiding handshaking and not hugging.

While they knew three of the WHO's 6 simple precautions - handwashing, good respiratory hygiene and physical distancing - they had not heard about avoiding touching one's face, home hygiene, quarantining/self-isolation and knowing COVID-19 hotspots. Their sources of knowledge were community social networks and local radio. Healthcare workers stated social media messages from external healthcare institutions and colleagues in Europe and North America, as additional sources of knowledge.

There were some misconceptions about the pandemic - these differed across social groups and were tied to rumours, common sense and cultural beliefs and religious practices. Within the JTHC group, some members noted a rumour circulating the community that wearing second hand clothing imported from China would cause infection. This rumour had developed from broader national discourse, via the mass media, about coronavirus originating from Wuhan, China. One JTHC member suggested "not walking late at night", since the virus was airborne and was likely to be more virulent at night.

A community member, of Yoruba heritage, dismissed the guidelines on respiratory hygiene noting in Yoruba:

'it is not a new thing to find people coughing. Coughing as a symptom of an illness has been in existence for a long time. Therefore, coronavirus is harmless'. "“Ṣé Òní ni àwon ènìyàn ti nwúkọ ni. Awon ènìàn ti nwúkọ fún İgbà pípẹ. Nítorínàà, coronavirus yì ko jẹ nkankan”)

The notion of coughing as an everyday occurrence and not a valid indicator of coronavirus infection was shared on traditional media, and rooted to some extent in common sense, particularly in a community like Ga Mashie where respiratory conditions associated with air pollution were common. This notion was further amplified and legitimated by limited public health information on how to recognise the "new continuous dry cough" (WHO, 2020) associated with coronavirus infection.

There was evidence of 'stigma consciousness' (Link \& Phelan, 2001) within the JTHC group. Some members observed that people who contracted the virus were likely to be shunned. By association, wearing a mask to protect oneself from infection could be misconstrued as being COVID-19 positive and therefore lead to stigma. Stigma arising from mask wearing was not observed or mentioned in later community engagement, possibly due to the government policy on mandatory mask wearing and the subsequent normalisation of the practice. However, one case was reported of a local woman presenting symptoms of COVID-19 at the government facility who fled after she realized she might be detained if she had contracted the virus².

Group discussions with the Christian and Muslim leaders suggested a strong tendency to view coronavirus risk through the lens of faith and God's protection. One Christian leader noted that 'Christian faith would curb the virus'. A Muslim leader suggested that Islamic ablution - the ritual washing of hands, feet and other body parts before Muslim prayer - negated the need for frequent handwashing as a strategy for coronavirus prevention. During subsequent days and weeks, identical ideas were reported by religious leaders across the country.

There was an association between these faith-based positions and a lack of organizational preparedness. Analysis of health facilities preparedness showed that faith-based organizations were not prepared for the pandemic. Leaders had educated their congregations on two precautions: handwashing and respiratory hygiene. But they had not invested in concrete prevention strategies, for example providing hand washing facilities or hand sanitizers and encouraging their elderly congregants or other vulnerable congregant groups to stay home. On $15^{\text {th }}$ March 2020, the government imposed a ban on all religious services. This reduced the potential risk posed by the lack of preparedness within faith-based institutions. At the time of writing the ban is still in place although there have been persistent attempts by national representatives of Christian and Islamic institutions to change the government's policy.

2) Personal communication from Stanley Bannerman-Blankson, frontline healthcare worker at Ussher Polyclinic, $14^{\text {th }}$ May 2020. 
The assessment of clinics, pharmacies, LCS shops and herbal shops showed that many were not prepared for the pandemic. 14 facilities had a private WC and running water. 8 facilities had limited types of personal protective equipment (PPE) - only masks in many cases. None of the facilities had patient education material and only 3 had trained all facility workers on COVID-19 risks and emergencies.

Scientific evidence from the WHO - which was supported by the Ghana Health Service - suggested that the most common symptoms of COVID-19 were a new continuous cough and/or high temperature/fever (above $37.8{ }^{\circ} \mathrm{C}$ ). Some patients were also likely to have breathing difficulties, tiredness and muscle aches, sore throat, nasal congestion and runny nose, and diarrhoea. Since these symptoms were associated with pre-existing and endemic conditions in the community like malaria, asthma and diarrhoeal diseases, and since $80 \%$ of COVID cases were mild or asymptomatic, it is likely that the primary care facilities we assessed would serve patients with a range of conditions, including asymptomatic COVID infection. The lack of healthcare systems level preparedness posed a high risk of exposure and infection for frontline healthcare workers as well as facility users.

\section{Material and Psychosocial Needs of Individuals Living With Chronic Conditions}

During the initial group discussion, JTHC members articulated three sets of needs: practical, medical and psychosocial. Practical needs included clear information about coronavirus, running water, affordable hand sanitisers, and space for self-isolation for infected individuals. Medical needs included access to emergency healthcare. Psychosocial needs included addressing anticipated stigma and managing intimate relationships.

During the psychosocial needs assessment, conducted three weeks later and during the period of lockdown in Accra, the set of articulated needs by JTHC members expanded to include nutritional and financial needs. Caregivers suggested limits to family support and the need for external social care.

Eleven JTHC members reported experiencing financial insecurities. Seven of these attributed their financial insecurities to the impact of the pandemic on their livelihood. Five members, who were market traders, spoke about sales decreasing significantly during the lockdown period.

"When this happened, there has been great financial difficulties. Things are hard, very hard. We don't have any money. With me I have two children I take care of so with the hardship, it is really affecting us but by God's grace we are surviving."

"It is very difficult. If you are not working, isn't it difficult? But what will you do? You have to stay home so you become healthy. Let us all pray so that God will take away this disease."

"We have run out of food...Nothing is going on well for us so I called my big brother and he sent me some money to buy food stuff at Agbogbloshie."

The majority of members also identified food insecurity as a major challenge. The community had received food packages distributed by local churches, local NGOs (e.g. RISE Ghana) and external NGOs (e.g. Food For All Africa). Some members received food packages; others did not. Those who did not receive food packages attributed access problems to ableism ( 5 members), ageism ( 2 members) and political factors (4 members). Some members observed that younger and able-bodied community members were able to queue for the food packages and/or engage in the physical efforts required to access food packages in crowded conditions. The implementation of food package distribution had not factored barriers posed by chronic illness and conditions of old age into community access. Others observed that food packages were distributed based on political party affiliation - therefore community members who belonged to the governing New Patriotic Party (NPP) ruling party were more likely to receive food packages, while those with affiliations to the opposition National Democratic Congress (NDC) party were not.

"When they share the food, some get and others too do not get...they are sharing the things but because of the chaos ...if you are giving to the elderly people, you have to come and put it in their hands. If it is not done like that, not everyone will get it." 
"They bring the items over here but they are doing politics with it. They brought the items to NPP people so they are those sharing them. They brought some things to share and they said they are sharing to the elderly men and women but at the end there was chaos."

The WHO (2020) guidelines on managing NCDs during the COVID pandemic include adhering to the afore-discussed 6 precautions, as well as the following: managing one's condition (e.g glucose control or blood pressure control); having a one-month supply of medication; having sufficient food and water; taking care of one's physical and mental health through physical activity and other healthy lifestyle practices; preparing for a health emergency by having all medical contact details to hand.

These guidelines assume that all individuals with NCDs have access to finances, social support and space to manage their conditions during a global pandemic. This was not the case for several group members. For those living in intergenerational households, clear strategies had been adopted to maintain home hygiene, respiratory hygiene and hand washing. Those using public bathroom facilities observed that while local interventions had been designed to maintain communal cleanliness, they cleaned these facilities before personal use.

"over here, we use public toilets. I use Dettol and parazone to clean the place before I use it."

Participants discussed evolving challenges to NCD care. Some members were worried and anxious about getting their medications and having laboratory tests done. Two individuals had to walk to their clinics for care, because they did not have enough money for transport. Two individuals were waiting for funds from caregivers in order to get laboratory tests done. Fifteen individuals had expired National Health Insurance Scheme (NHIS) cards or cards that were about to expire. The NHIS card covered the costs of a restricted set of generic diabetes and hypertension medications. It did not cover the costs of more expensive medications, laboratory tests and medical consultations. Financial insecurity was a major barrier to accessing NCD care pre-COVID because health protection offered through NHIS was limited - and the same dynamics applied within the COVID-19 context.

"I went to see the doctor on $7^{\text {th }}$ April but I have only about five pills to take before running out of medications. Now they say we cannot go out so, if you can buy it for me then I am done."

Of the 5 caregivers we interviewed, only one had comprehensive knowledge about their relatives' conditions and treatment regimes, and none had practical plans and resources in place for emergencies. Four caregivers did not know the names of the medicines their relatives took or the current medical status of their relatives. This had implications on quality of care.

"Honestly, I am not sure I can remember the drugs she [mother] takes now. I used to know but I have forgotten. Sometimes the burden on me is high with my children so I forget. Right now I cannot tell you the drugs she is taking"

Most members were worried and anxious about exposure and infection. The majority of members were staying indoors and protecting themselves from infection. However, there was a shared anxiety about high levels of risk outside and community youth were perceived as conduits for exposure and risk. Most members lived in large households; therefore, loneliness and social isolation were not the most salient experiences. One member reported feeling socially overwhelmed as he was constantly called upon, in his position as a community leader, to give advice on coronavirus related matters.

"We do not see the disease but we hear about it on the radio that it is very dangerous so we have to protect ourselves."

"the way they are saying it, the disease is very dangerous but some of our people do not understand things. Now they say we should all stay at home but some people will say they are going to town...they are doing this and that."

"The stress is a lot. There is no money and because of the lockdown too you can't go anywhere to get money...the social duties will be there and people always coming to me with their problems 
they are facing and I have to be moving up and down. So as for me, I don't get time for myself at all to take care of my health."

\section{Productive Alliances for COVID-19 Support in the Community}

In Table 3 we present the list of internal and external actors who are likely to provide COVID-19 support to JTHC and the community, based on the narratives of research participants and our observations of official COVID-19 responses in the community.

Table 3

Identified Productive Alliances for COVID Preparedness in Ga Mashie

\begin{tabular}{|c|c|}
\hline Productive alliances & COVID Care \\
\hline $\begin{array}{l}\text { Bonding social capital } \\
\text { (within Ga Mashie) }\end{array}$ & $\begin{array}{ll}\text { - } & \text { Jamestown Health Club (JTHC) } \\
\text { - } & \text { Local Churches } \\
\text { - } & \text { Local NGOs (e.g. RISE Ghana) and external NGOs (e.g. Food For All } \\
\text { Africa) }\end{array}$ \\
\hline $\begin{array}{l}\text { Bridging and Linking social capital } \\
\text { (between Ga Mashie and (a) similar marginalised groups and communities } \\
\text { and (b) national and global champions) }\end{array}$ & $\begin{array}{ll}\text { - } & \text { Food and Drugs Authority (FDA) } \\
\text { - } & \text { Ghana Health Service (GHS) } \\
\text { - } & \text { Ministry of Gender Children and Social Protection (MoGCSP) } \\
\text { - } & \text { Accra Metropolitan Assembly } \\
\text { - } & \text { Ga Traditional Council } \\
\text { - } & \text { Ghana NCD Alliance } \\
\text { - } & \text { COVID-19 National Fund } \\
\text { a }\end{array}$ \\
\hline
\end{tabular}

listed based on assessment of national responses

\section{Productive Alliances Within Community}

JTHC members mentioned the role of two local churches in facilitating the distribution of food packages to community members. Some of the church activities were conducted as part of the government's food distribution programme which was implemented as a collaboration between government ministries (Ministry of Gender Children and Social Protection (MoGCSP), Metropolitan Assemblies and civil society (NGOs, Faith-based Organizations (FBOs)). Churches were also important actors because of the religious and spiritual support they provided. Most participants processed their anxiety and fears through their religious faith, as quotes in the previous section showed.

Two NGOs - RISE Ghana and Food For All Africa - supported the distribution of food in the community.

We included JTHC on the list of community-level productive alliances because some members were providing psychosocial support to each other. While this did not address more pressing material needs this form of support had symbolic value and highlighted the importance of existing social support networks during crises.

\section{Productive Alliances Between the Community, Other Marginalised Communities and External Actors}

We identified four national and city level organizations who were active facilitators of bridging and linking social capital for Ga Mashie and other poor communities: Food and Drugs Authority (FDA); Ghana Health Service (GHS); Ministry of Gender Children and Social Protection and Accra Metropolitan Assembly (AMA). These government sector institutions were directly involved in providing risk reduction and safety information on COVID-19, facilitating the distribution of food packages, and cleaning and disinfecting public spaces such as markets and lorry parks.

Our analysis also revealed limitations to the national level efforts. First, the implementation of food distribution was uneven, as observed by JTHC members. Food packages did not reach all community members. No additional relief was supplied beyond food. Secondly, established local NGOs, such as the Ga Mashie Development Agency (GAMADA), and traditional organizations such as the Ga Traditional Council were excluded from coordination and implementation. This was striking, as both played pivotal developmental roles in the community. 
Thirdly, while the relationship between NCDs and COVID-19 was addressed in government narratives in later months, and national groups like GhNCDA advocated on this issue, no concrete attempts were made at developing interventions to address vulnerable groups living with chronic conditions.

While the COVID-19 National Fund was established for poor and vulnerable communities like Ga Mashie, social protection interventions had not been articulated and implemented at the time of writing.

The policy position on implementing pro-poor COVID-19 strategies was further undermined by contradictory anti-poor actions. In the middle of the partial lockdown, AMA undertook a demolition exercise in Agbobloshie, a neighbouring community to Ga Mashie with social and occupational links. The primary aim was to dredge a local lagoon in order to minimise the impact of flooding during the impending rainy season. However, residents in the affected areas were rendered homeless. The timing of this exercise was widely condemned, as the government had effectively created conditions for increasing the risk of exposure and infection, and deepening social and financial insecurities, for the most vulnerable communities it purported to protect.

\section{Discussion and Conclusions}

Our study aimed to: (1) examine community understandings of COVID-19 risk, treatment and care; (2) assess the needs of JTHC members; (3) assess available community and national resources available to support the group during the pandemic; and (4) offer practical recommendations for community support.

Community understandings were limited with respect to the global (WHO) and national (GHS) public health guidelines on COVID-19 and there were gaps and misunderstandings regarding transmission, risk and medical outcomes. However, COVID-19 was understood as a new public health threat and individuals drew on a broad and eclectic range of sources, beyond public health, to make sense of this. Community members blended cultural, religious, common sense, medical and political knowledge in their understanding of COVID-19. Sources of knowledge included family and social networks, traditional and social media, and local and external pluralistic healthcare systems.

Aspects of the new knowledge shaped concrete risk-reduction practices, from handwashing to staying at home. Other aspects potentially raised risk for the community, such as stigma consciousness and stigmatising practices.

JTHC members had material and psychosocial needs. Members were anxious and worried about risk of infection and welcomed psychosocial support. They also requested material support: money, food and access to NCD treatment. Previous research on CVD in the community suggests that psychosocial needs are easier to address compared to material needs, albeit with committed time and support from support groups outside the community (de-Graft Aikins et al., 2020). What has been difficult to provide is sustained material support - medicines, medical technologies, food and money for everyday expenses. These challenges are likely to persist for COVID-19 support.

Apart from the early distribution of food, no further relief was provided to the community. Pro-poor COVID policy was more rhetorical than evidence-based and action oriented. The financial, food and medical insecurities of vulnerable individuals and communities, which pre-dated COVID but have intensified during the pandemic, remain to be comprehensively addressed. Implementation activities did not build on best practices per national policies on social and health protection such as the Livelihood Empowerment Against Poverty (LEAP) programme, which offer safety nets for 'poorest of the poor' and elderly, and the new mental health and NCD policies that focus on rights-based health protection.

We recommend two practical solutions. In the immediate term, the solution will be to negotiate access to the COVID-19 National Fund for Ga Mashie residents who fit the 'needy and vulnerable' criteria. In the longer term, post COVID-19 crisis, support for these communities has to be negotiated through existing social and health protection policies.

Cornish and Ghosh (2007) argue that within historically marginalised communities a "structured ecology of power" holds groups in "fractured and unequal set of interdependencies" that necessitate the involvement of more powerful others to effect concrete change. Campbell and Murray (2004) argue that to improve opportunities for health in marginalised settings, 'adversarial strategies may often be necessary' - and these require challenging, rather than 
cooperating with, relevant power-holders. We argue for a blended approach that is informed by context, history and a critical examination of the structured ecology of power within communities of power holders.

Productive alliances between Ga Mashie, other vulnerable communities and interlocuters with access to the powerbrokers of the current COVID-19 national response are necessary to ensure community safety, security and equitable healthcare during the pandemic. We have identified potential 'national champions' who can drive the short-term response and outlined the scope and limits of their negotiating power.

The longer-term responses will be more difficult and will require further critical research. It is well documented that there is an extensive lag period between the development and implementation of health and public policy in Ghana (de-Graft Aikins \& Koram, 2017). Current policies on mental health, disability rights and NCDs took at least a decade to be developed and equally as long to be implemented. Policy monitoring and evaluation, and the scaling up of successful interventions take even longer if they do occur at all. These delays and challenges are usually driven by governance processes that are entrenched in policy discontinuities dating from the colonial era. They are also driven by power struggles, and "fractured and unequal set of interdependencies", between policymakers, politicians and 'development partners' - in terms of naming, understanding and funding local problems.

COVID-19 appears to have accelerated the implementation of targeted developmental strategies and plans, and there has been visible engagement between the government and the local scientific community (Ofori-Adjei et al., 2020). However, as this study has highlighted, established barriers to equitable healthcare and social protection for marginalised communities still operate. Strategies to address the immediate and post-COVID needs of vulnerable communities will have to focus on the politics and practicalities of implementing existing rights-based policies that intersect health, poverty reduction and social protection.

Funding: The authors have no funding to report.

Acknowledgments: The authors have no support to report.

Competing Interests: The authors have declared that no competing interests exist.

\section{References}

Alidu, S., Dankyi, E., \& Tsiboe-Darko, A. (2016). Aging policies in Ghana: A review of the Livelihood Empowerment Against Poverty and National Health Insurance Schemes. Ghana Studies, 19, 154-172. https://doi.org/10.1353/ghs.2016.0007

Awuah, R. B., Anarfi, J. K., Agyemang, C., Ogedegbe, G., \& de-Graft Aikins, A. (2014). Prevalence, awareness, treatment and control of hypertension in urban poor communities in Accra, Ghana. fournal of Hypertension, 32(6), 1203-1210.

https://doi.org/10.1097/HJH.0000000000000165

Braveman, P. (2020). COVID-19: Inequality is our pre-existing condition. UNESCO.

https://en.unesco.org/inclusivepolicylab/news/covid-19-inequality-our-pre-existing-condition

Bukhman, G., Mocumbi, A. O., \& Horton, R. (2015). Reframing NCDs and injuries for the poorest billion: A Lancet commission. Lancet, 386, 1221-1222. https://doi.org/10.1016/S0140-6736(15)00278-0

Campbell, C. (2020). Social capital, social movements and global public health: Fighting for health-enabling contexts in marginalised settings. Social Science \& Medicine, 257, Article 112153. https://doi.org/10.1016/j.socscimed.2019.02.004

Campbell, C., \& Jovchelovitch, S. (2000). Health, community and development: Towards a social psychology of participation. fournal of Community \& Applied Social Psychology, 10, 255-270.

https://doi.org/10.1002/1099-1298(200007/08)10:4<255::AID-CASP582>3.0.CO;2-M

Campbell, C., \& Murray, M. (2004). Community health psychology: Promoting analysis and action for social change. fournal of Health Psychology, 9(2), 187-195. https://doi.org/10.1177/1359105304040886

CitiNewsroom. (2020, May 26). Over GHS50.6M donated to COVID-19 Trust Fund - Sophia Akuffo. https://citinewsroom.com/2020/05/over-ghs50-6m-donated-to-covid-19-trust-fund-sophia-akuffo/ 
Clark, A., Jit, M., Warren-Gash, C., Guthrie, B., Wang, H. H. X., Mercer, S. W., Sanderson, C., McKee, M., Troeger, C., Ong, K. L., Checchi, F., Perel, P., Joseph, S., Gibbs, H. P., Banerjee, A., Eggo, R. M., \& Centre for the Mathematical Modelling of Infectious Diseases COVID-19 working group. (2020). Global, regional, and national estimates of the population at increased risk of severe COVID-19 due to underlying health conditions in 2020: A modelling study. Lancet Global Health, 8, e1003-e1017. https://doi.org/10.1016/S2214-109X(20)30264-3

Cornish, F., \& Ghosh, R. (2007). The necessary contradictions of 'community-led' health promotion: A case study of HIV prevention in an Indian red light district. Social Science \& Medicine, 64(2), 496-507. https://doi.org/10.1016/j.socscimed.2006.09.009

de-Graft Aikins, A., \& Akoi-Jackson, B. (2020). "Colonial Virus": COVID-19, creative arts and public health communication in Ghana. Ghana Medical fournal, 54(4, Suppl.), 86-96. https://doi.org/10.4314/gmj.v54i4s.13

de-Graft Aikins, A., Awuah, R. B., Pera, T. A., Mendez, M., \& Ogedegbe, G. (2015). Explanatory models of diabetes in urban poor communities in Accra, Ghana. Ethnicity \& Health, 20, 391-408. https://doi.org/10.1080/13557858.2014.921896

de-Graft Aikins, A., \& Koram, K. (2017). Health and healthcare in Ghana, 1957-2017. In E. Aryeetey \& R. Kanbur (Eds.), The economy of Ghana: Sixty years after independence (pp. 365-384). Oxford, United Kingdom: Oxford University Press.

de-Graft Aikins, A., Kushitor, M., Boatemaa, S., Sanuade, O., Asante, P. Y., Sakyi, L., Agyei, F., Koram, K., \& Ogedegbe, G. (2020). Building cardiovascular disease (CVD) competence in an urban poor Ghanaian community: A social psychology of participation approach. Journal of Community \& Applied Social Psychology, 30(4), 419-440. https://doi.org/10.1002/casp.2447

Fernandez, E. R. (2020, August). Blame poverty, not the poor, for COVID-19's spread in Brazil's Amazon. Scientific American. https://www.scientificamerican.com/article/blame-poverty-not-the-poor-for-covid-19s-spread-in-brazils-amazon

International Monetary Fund. (2020). IMF Executive Board approves a US\$1 billion disbursement to Ghana to address the COVID-19 Pandemic [Press Release No. 20/153]. https://www.imf.org/en/News/Articles/2020/04/13/pr20153-ghana-imf-executive-board-approves-a-us-1-billion-disbursement-toghana-to-address-covid-19

Jovchelovitch, S. (2002). Re-thinking the diversity of knowledge: Cognitive polyphasia, belief and representation. Psychologie et société, 5(1), 121-138.

Kenu, E., Frimpong, J. A., \& Koram, K. A. (2020). Responding to the COVID-19 pandemic in Ghana. Ghana Medical fournal, 54(2), 72-73. https://doi.org/10.4314/gmj.v54i2.1

Link, B., \& Phelan, J. (2001). Conceptualising stigma. Annual Review of Sociology, 27, 363-385. https://doi.org/10.1146/annurev.soc.27.1.363

Lloyd-Sherlock, P., Ebrahim, S., Geffen, L., \& McKee, M. (2020). Bearing the brunt of COVID-19: Older people in low- and middleincome countries. British Medical fournal, 368, Article m1052.

Oduro-Mensah, E., Tetteh, J., Adomako, I., Adjei-Mensah, E., Owoo, C., Yawson, A. E., Lartey, M., \& the COVID-19 Collaborators. (2020). Clinical features of COVID-19 in Ghana: Symptomatology, illness severity and comorbid non-communicable diseases. Ghana Medical fournal, 54(4, Suppl.), 23-32. https://doi.org/10.4314/gmj.v54i4s.5

Ofori-Adjei, D., Lartey, M., \& Koram, K. A. (2020). Ghana and the COVID-19 pandemic. Ghana Medical fournal, 54(4, Suppl.), 1-2. Sanuade, O., Dodoo, F., Koram, K., \& de-Graft Aikins, A. (2021). Explanatory models of stroke in Ghana: Perspectives of stroke survivors and their caregivers. Ethnicity \& Health, 26(5), 697-719. https://doi.org/10.1080/13557858.2018.1557116

World Health Organization (WHO). (2020). Coronavirus disease (COVID-19) Weekly Epidemiological Update and Weekly Operational Update [accessed 30th August 2020]. https://www.who.int/emergencies/diseases/novel-coronavirus-2019/situation-reports 


\section{Appendices}

\section{Appendix 1: Checklist for Community Healthcare Providers}

Box 2

Checklist Questions for Community Healthcare Providers

- do you have patient information posters in your facility?

- do you have basic information about COVID-19 for all of your workers?

- $\quad$ are all your workers trained on COVID-19?

- do you have personal protective equipment (PPE)?

- do you have fluid resistant surgical masks (FRSM)?

- do you have disposable gloves?

- do you have disposable plastic aprons?

- do you have a private WC in your facility?

- do you have running water - for flushing and emergency cleaning?

- do you have detergent and disinfectant?

- do you have cloths, mops, buckets for emergency cleaning?

- $\quad$ are cleaners and general assistants trained to respond to emergencies that require cleaning?

- what are your specific needs with respect to COVID-19 preparedness?

\section{Appendix 2: Psychosocial Needs Assessment Guide for Jamestown Health Club (JTHC) Members}

1. Introduction

- Introduce yourself, establish how to address the participant and the language for communicating,

- State the aim of the call: psychosocial support being offered by the JTHC team for members. Mention initial sessions conducted last week by the JTHC team.

- Set the context for the call: for example, "today I am calling to find out how you are doing and to see whether you have any needs or problems". You can remind the participant that when the JTHC engaged with them four weeks ago, before the lockdown, we said we would follow up to check on their wellbeing.

2. Needs assessment (focus on material, medical and psychological)

Explore what participant's current needs are: financial, nutritional, medical, care arrangements etc.

- Probe on food and public sanitation (as these have come up in previous sessions):

- In the initial sessions we have learned that some people have not been able to get the government food parcels. Have you had the same problems?

- We have also heard some people are worried about how to keep their shared toilets and bathhouses clean. What have your experiences been?

- Probe on medicines

- What medicines do you take? [make a list]

- Where do you usually buy the medicines? [get specific names]

- Do you have supplies for the next one month?

- Do you have National Health Insurance? Is it active?

- Who will buy medicines for you if you cannot go outside? [get specific names and contact numbers]

- Explore and address feelings of isolation, anxiety, fear

- How are you feeling generally? Let participant speak about their psychological state in their own way. Then probe if they state anxiety, fear etc.

- What are the sources of anxiety? Probe and address

- What is causing feelings of isolation? Probe and address 
3. Debriefing

- Ask if participant has any questions about the phone call, if there are other issues they wish to raise.

- Find out whether participant has mobile money enabled on their phone. Explain that we are trying to ensure that when the government promises financial help we can advocate for them to be recipients.

- If you are asked for help or advocacy say you will speak to the JTHC Team and provide answers in a follow up call. 